http://jmscr.igmpublication.org/home/ ISSN (e)-2347-176x ISSN (p) 2455-0450

crossref DOI: https://dx.doi.org/10.18535/jmscr/v8i2.11

Journal Of Medical Science And Clinical Research

\title{
Study of serum uric acid in Type 2 diabetes mellitus
}

Authors

\section{Dr Uddhav Khaire ${ }^{1}$, Dr Rahul Rathod ${ }^{2}$, Dr Pramod Wattamwar ${ }^{3}$}

${ }^{1}$ MD Medicine, Asso. Professor, Department of General Medicine, Government Medical College and Hospital, Aurangabad, India

${ }^{2}$ MD Medicine, Ass. Professor, Department of General medicine, Government Medical College and

Hospital, Aurangabad, India

${ }^{3}$ MD Medicine, Junior Resident, Department of General medicine, Government Medical College and

Hospital, Aurangabad, India

\begin{abstract}
Diabetes Mellitus (DM) is a metabolic disorder characterized by the presence of chronic hyperglycemia associated with impairment in the metabolism of carbohydrates, lipids and proteins. Uric acid is the end product of purine catabolism. Excessive serum uric acid accumulation can cause various diseases. For more than 50 years, increased serum levels of uric acid have been implicated in cardiovascular disease. Different mechanisms have been suggested through which uric acid may be involved in the atherosclerotic process and its clinical complications. Uric acid may act as a pro-oxidant, particularly at increased concentrations, and may be a marker of oxidative stress. The Morbidity and mortality due to non-communicable diseases specially attributed to diabetes mellitus and coronary heart disease is rising rapidly in India, causing nearly 5.8 million deaths per year annually. Considering the strong association between the levels of serum uric acid and the occurrence of coronary atherosclerosis in subjects with type 2 diabetes mellitus, the current study has been undertaken to assess the factors influencing the serum uric acid levels in patients with type 2 diabetes mellitus.
\end{abstract}

Objectives: To find out association between serum uric acid level and type 2 Diabetes Mellitus. Also correlate serum uric acid level to duration of type 2 Diabetes Mellitus.

Materials and Methods: This was a Case control study comparing between two groups of age and sex matched population.

Results: The mean serum uric acid level of diabetes mellitus of cases 5.10 and that of controls is 3.73 and the p value is 0.04 which is statistically significant. It shows that as duration of DM increases there is significant rise in Serum Uric acid level

Conclusion: Also there is a significant positive correlation between the levels of serum uric acid duration of DM and comorbidities in type 2 DM.

\section{Introduction}

Diabetes Mellitus (DM) is an important health issue today. According to World Health Organization (WHO), the number of people with diabetes has increased from 177 million in 2010 to
326.5 million in 2017 , in the age group of 20-64 years. It is expected that the number will be around 438 million by the year 2040. In 2017 alone is considered, China is the country with highest number of people with diabetes, with114 
million people suffering from DM. Next to China, India has the next highest number. India contributes $49 \%$ of the world's diabetes burden, with around 72 million in 2017 .The data show that the number is expected to increase to 134 million by $2025^{1}$.

$\mathrm{DM}$ is a leading cause of morbidity and mortality worldwide ${ }^{2}$. About 2-3\% of the world's population is estimated to have $\mathrm{DM}^{3}$. People with DM are at higher risk for cardiovascular disease, nephropathy and retinopathy ${ }^{3,4}$.

Serum Uric acid is the final oxidation product of purine metabolism in the circulation. Elevated serum uric acids levels are associated with increased risk for cardiovascular disease and so the metabolic diseases such as metabolic syndrome and diabetes mellitus ${ }^{5}$. Patients with hyperuricemia are significantly more likely to $\mathrm{DM}^{6}$. Some study suggests uric acid may be associated with glycometabolic disorders, because of this association between uric acid and glucose metabolic ${ }^{7}$.

However, among patient with diabetes mellitus type 2, uric acid levels tend to decline with increasing blood glucose concentration 8 . The reason for the inverse relationship is unclear. However, insulin levels are also closely related to uric acid levels ${ }^{9}$. Serum uric acid levels are directly associated with serum insulin levels in diabetic, but the mechanism for this is not clear ${ }^{10}$. We aimed to determine if there is an association between $\mathrm{HbA} 1 \mathrm{c}$ and uric acid among patients with diabetes mellitus type 2 who attend a tertiary care center in Aurangabad city, Maharashtra.

\section{Aim}

To find out association between serum uric acid level and type 2 Diabetes Mellitus. Also correlate serum uric acid level to duration of type 2 Diabetes Mellitus.

\section{Material and Methods}

This was a Case control study comparing between two groups of age and sex matched population. Controls were both age and sex matched to the cases. A total of 140 cases were selected who were admitted to a tertiary care center and corresponding age and sex matched non-diabetic controls were selected.

\section{Result}

\section{Demographic data}

140 cases and controls were analysed for this study. Mean age in case group was 58.13 while in control group it was 57.98.As it was a sex matched control group both group had 56 males and 84 females.

Table: 1 Demographic data of cases and control population

\begin{tabular}{|l|c|c|}
\hline & Cases & Control \\
\hline Age & $58.13 \pm 12.55$ & $57.98 \pm 12.95$ \\
\hline Male & 56 & 56 \\
\hline Female & 84 & 84 \\
\hline
\end{tabular}

The mean serum uric acid level of diabetes mellitus of cases 5.10 and that of controls is 3.73 and the $p$ value is 0.04 which is statistically significant.

Table 2: Comparison of serum uric acid between cases \& controls

\begin{tabular}{|c|c|c|c|c|c|c|c|}
\hline \multirow{3}{*}{$\begin{array}{l}\text { Sr. } \\
\text { Acid }\end{array}$} & \multirow[t]{3}{*}{ Uric } & Group & $\mathbf{N}$ & Mean & $\begin{array}{c}\text { Std. } \\
\text { Deviation }\end{array}$ & $\begin{array}{c}\text { Std. Error } \\
\text { Mean }\end{array}$ & $p$ value \\
\hline & & Control & 140 & 3.73 & 0.31 & 0.03 & \multirow{2}{*}{0.04} \\
\hline & & Cases & 140 & 5.10 & 01.00 & 0.08 & \\
\hline
\end{tabular}




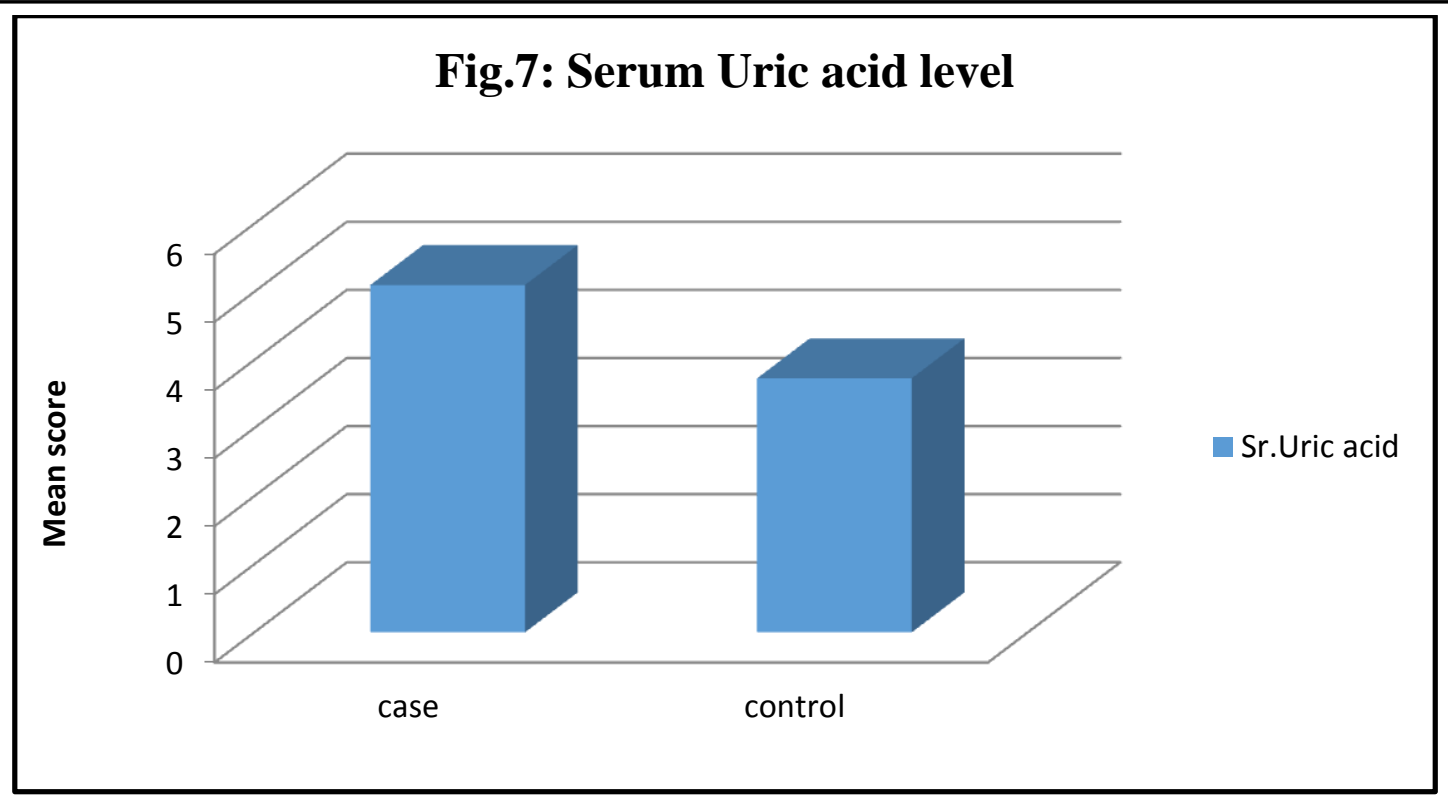

The Following table shows that most no. of samples $(57.86 \%)$ having 1-5 years of duration of DM followed by 6-10 years of DM constitute $31.43 \%$ of samples.

The highest mean score was observed in 11-15 years of DM duration which was 6.79 and standard deviation was 0.37 . Further there was significant association found between all groups except for 1-5 years. It shows that as duration of DM increases there is significant rise in Serum Uric acid level

\section{Correlation between Serum Uric Acid and Duration of diabetes}

\begin{tabular}{|l|c|c|c|c|}
\hline \multirow{2}{*}{ Duration of DM } & \multirow{2}{*}{ No. of Samples } & \multicolumn{2}{c|}{ Hyperuricemia } & \multirow{2}{*}{ p-value } \\
\cline { 3 - 4 } & & Mean & SD & \\
\hline 1-5 years & $81(57.86 \%)$ & 4.47 & 0.60 & 0.997 \\
\hline 6-10 years & $44(31.43 \%)$ & 5.71 & 0.69 & $0.005^{* *}$ \\
\hline 11-15 years & $11(07.86 \%)$ & 6.79 & 0.37 & $0.003^{* *}$ \\
\hline 16-20 years & $04(02.86 \%)$ & 6.48 & 0.61 & $0.004^{* *}$ \\
\hline
\end{tabular}
* Correlation is significant at the 0.05 level (2-tailed)
Correlation is significant at the 0.01 level (2-tailed).

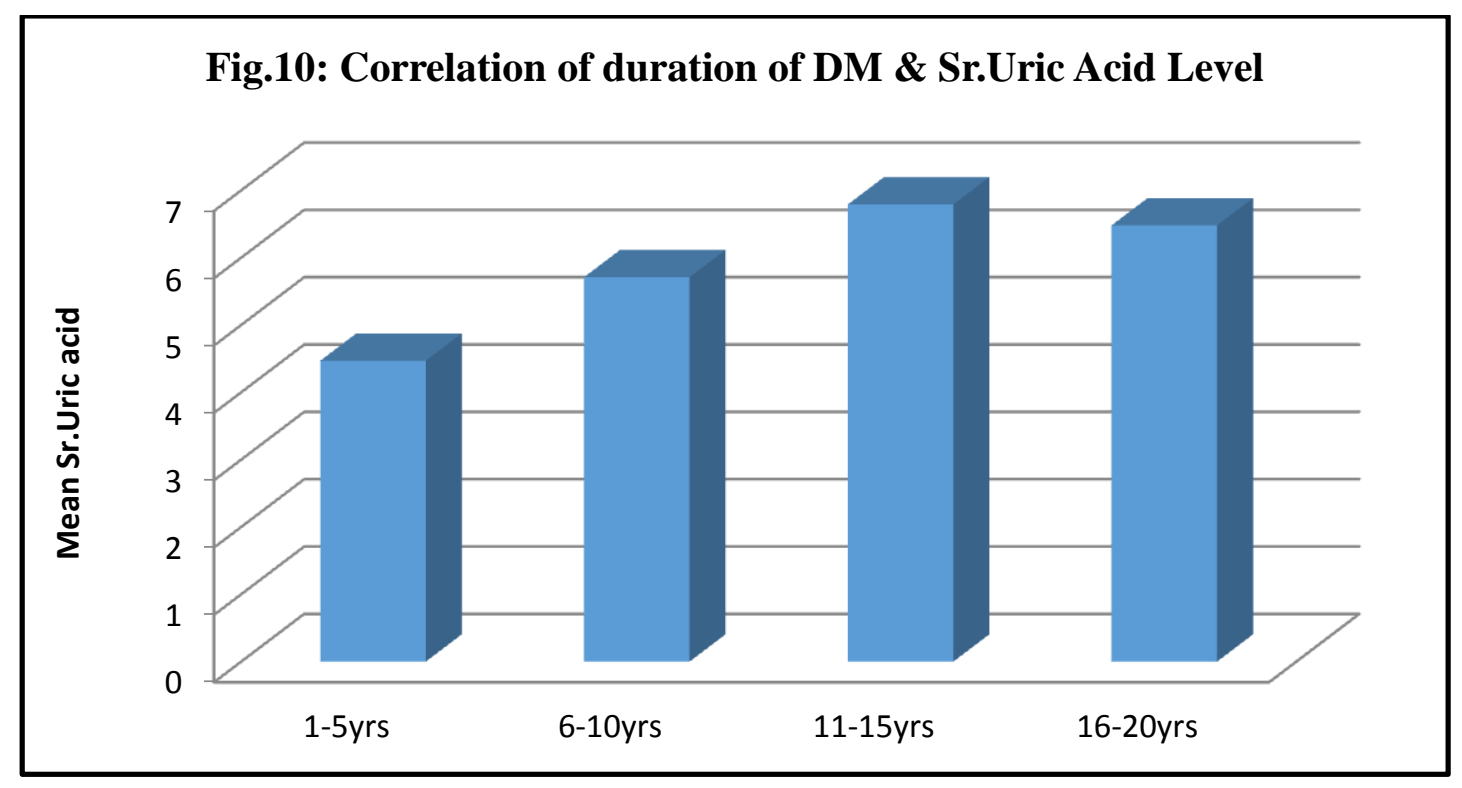




\section{Discussion}

The need for early indicators of diabetic complications is essential to prevent late complications and their detrimental / deleterious effects. There is need for sensitive serum markers that are associated with diabetes and its complications. Estimation of these parameters helps in early intervention, thereby delaying / reverting the chronic complications of diabetes in the early stages.

Elevated serum uric acid level can result from no. of factors including both acute and chronic causes. Acute causes of hyperuricemia include the intake of large amount of alcohol, tumour lysis syndrome (a complication of cancer chemotherapy) and a diet that is high in purines or proteins. Alternatively, chronic hyperuricemia can result from conditions that cause a reduction in the glomerular filtration rate, a decrease in the excretion of uric acid or an increase in overall tubular absorption ${ }^{11}$.

Several mechanism have been proposed on how uric acid is elevated, Rosolowsky showed increased serum uric acid with decreasing renal function ${ }^{12}$ anddefect in URATI transporter which is responsible for urate reabsorption from Kidney ${ }^{13}$.Elevated levels of uric acid have been shown to be an independent marker in many conditions like hypertension ${ }^{14}$, DM, stroke ${ }^{15}$, cardiovascular disease ${ }^{16}$ and renal disease. It remains unclear whether an elevated uric acid concentration contributes to the development of these conditions or whether it is a consequences of these conditions.

Hyperglycemia is a well-known risk factor for hyperuricemia ${ }^{17}$ and also hyperuricemia is a risk factor for the development of diabetes. Such counter influence leads to a vicious cycle, which may drive the development of co-morbidities such as Cardiovascular disease (CVD) in general and Coronary artery disease (CAD) in specific.

In this cross sectional study, 140 patients with type 2 diabetic mellitus were taken as cases and 140 non diabetic individuals were taken as controls. This study evaluated the levels of serum
Uric acid in type 2 diabetic mellitus and compared them with non-diabetic controls. The serum uric acid level was compared in the two groups and also duration of DM and respective serum uric acid was studied in the cases.

The serum uric acid level was found to be increased in diabetic patients than the non-diabetic individuals and was statistically significant $(p<0.05)$. Similar results were observed in various other studies such as done by Srivastava and Dixit $^{18}$, Kumari and Sankaranarayana ${ }^{19}$ which also reported higher serum uric acid levels in Type 2 diabetics than in normal controls. Furthermore, in the study done by Rao and Vanukuri ${ }^{20}$, it was reported that serum uric acid levels are significantly elevated in diabetics.

Patients with longer duration of diabetes were more susceptible to develop various complications including hyperuricemia ${ }^{21}$. Our study also shows that higher level of serum uric acid was seen in patients with longer duration of diabetes and it was also found significant.

Strength of present study- simple cost effective biochemical test like uric acid is used, which can guide the deterioration in glucose metabolism instead of using complex tests for measurement of insulin resistance.

\section{Conclusion}

In the present study, the levels of serum uric acid and other blood profile were evaluated in type 2 diabetic mellitus mellitus patients and healthy individuals. The serum levels of Uric acid were raised in type 2 diabetic cases when compared to non-diabetic control group indicating significant changes in type 2 diabetic mellitus mellitus patients. Also there is a significant positive correlation between the levels of serum uric acid with sr. creatinin, duration of DM and comorbidities in type $2 \mathrm{DM}$.

Hyperuricemia is one of significant risk factors which can lead to possible cardiovascular disease and increase the morbidity and mortality in type 2 DM. So treatment of hyperuricemia may prevent or decrease the development of cardiovascular 
disease in type 2 DM. Further research is needed to determine the assessment and treatment of hyperuricemia for reducing the risk of cardiovascular disease in type 2 DM.

\section{References}

1. Ahmed AM (2002) History of diabetes mellitus. Saudi Med J 23: 373- 378.

2. Diabetes mellitus history- from ancient to modern times.

3. Patlak M (2002) New weapons to combat an ancient disease: treating diabetes. FASEBJ 16: 1853

4. Maitra A, Abbas AK (2005) Endocrine system. Robbins and Cotran Pathologic basis of disease (7thedtn). Saunders, Philadelphia. 1156-1226.

5. Chen L, Magliano DJ, Zimmet PZ (2014) The worldwide epidemiology of type 2 diabetic mellitus mellitus: present and future perspectives. Nature reviews endocrinology

6. Ramachandran A, Snehalatha C, Shetty AS, et al.Trends in prevalence of diabetes in Asian countries.World $\mathbf{J}$ Diabetes. 2012;3(6):110-7. doi:10.4239/wjd.v3.i6.110.

7. Gupta R, Misra A. Type 2 diabetic mellitus in India: Regional disparities. Br J DiabetesVasc Dis. 2007;7:12-6. 6.

8. Joshi SR, Das AK, Vijay VJ, et al. Challenges in diabetes care in India: sheer numbers, lack of awareness and inadequate control. J Assoc Physicians India. 2008;56:443-50.

9. Thankappan KR, Shah B, Mathur P, et al. Risk factor profile for chronic noncommunicable diseases: results of a community-based study in Kerala, India.Indian J Med Res. 2010;131:53-63

10. K Park et al. Diabetes mellitus, in park`s text book of preventive and the social medicine, 20 ed. Jabalpur, M/s Banarasidas Bhanos publication, 2009, pp 341-345.
11. Richard J. Johnson et.al., Is there pathogenic role for uric acid in hypertension and cardiovascular and renal disease?, Hypertension, 2009; 41: 11831190.

12. Elizabeth T. Rosolowskyet.al., High normal Serum uric acid is associated with Impaired glomerular filtration Rate in Non-protein uric patients with Type I diabetes. Clin J Am Soc Nephrol, 2008; 3: 706-713.

13. Carmine Zoccali et.al., Uric acid and endothelial dysfunction in essential hypertension, J Am Soc Nephrol, 2006;17: 1466-1471.

14. Carmine Zoccali et.al., Uric acid and endothelial dysfunction in essential hypertension, J Am SocNephrol, 2006;17 : 1466-1471.

15. Seppo Lehto et.al. Serum uric acid is a strong predictor of stroke in patient with Non-Insulin dependent Diabetes mellitus, Stroke, 1998; 29: 635-639.

16. Saijo Y. et.al., Relationships of C-reactive protein, uric acid and glomerular filtration rate to arterial stiffness In Japanese subjects, Journal of human hypertension, 2005; 17: S165-S168.

17. Chizyński K, Rózycka M., [Is hyperuricemia a cardiovascular risk factor?], WiadLek. 2006;59(5-6):364-7.

18. Srivastava TR, Dixit RK. Role of serum uric acid and nitric oxide in the diagnosis of Type 2 diabetic mellitus mellitus-a case control study. Natl J Physiol Pharm Pharmacol. 2017;7(2):170-3.

19. Kushiyama A, Tanaka K, Hara S, Kawazu S. Linking uric acid metabolism to diabetic complications. World J Diabetes. 2014; 5(6):787-795. doi:10.4239/wjd.v5.i6.787

20. Rao TM, Vanukuri NK. A study on serum uric acid levels in Type 2 diabetic mellitus mellitus and its association with cardiovascular risk factors. Int Arch Integr Med. 2016;3(12):148-55. 
21. Kushiyama A, Tanaka K, Hara S, Kawazu S. Linking uric acid metabolism to diabetic complications. World J Diabetes. 2014; 5(6):787-795. doi:10.4239/wjd.v5.i6.787. 